\title{
Craving for Quality Education in Tanzania: Dispelling the Myths
}

\author{
John Fungulupembe Kalolo (Corresponding author) \\ Psychology and Curriculum Studies Unit, Faculty of Education \\ Mkwawa University College of Education, Tanzania \\ E-mail:mwakalolo@yahoo.ca
}

Received: October 29, 2015 Accepted: January 4, 2016 Published: January 23, 2016

doi:10.5296/jei.v2i1. $8506 \quad$ URL: http://dx.doi.org/10.5296/jei.v2i1.8506

\begin{abstract}
There has been widespread concern about the provision of quality education (QE) for all learners in all contexts, but research evidence to inform this debate is quite divergent and in most of cases the question about achieving this desire seems to be full of myths. This paper examines a selection of embedded myths about QE in Tanzanian education sector. The paper specifically aims at identifying the myths, their effects in education practice, and the appropriate ways to address them. The researcher's own experiences and voices from secondary school teachers, parents, and students were merged to inform the study. Merging of these voices helped this paper to have a major contribution towards a better understanding of myths and their adverse influence in education practice, and spotting some alternative modes of practice towards addressing them.
\end{abstract}

Keywords: Myths, Educational myths, Quality education

\section{Introduction}

Tanzania is one of the countries in the Southern African Development Community (SADC) region which has made clear her intentions to provide quality education in all schools. It is almost five and a half decades since Tanzanian independence, the period which marks the beginning of efforts to improve the quality of education Tanzania. Examples of such efforts include the devotion of more resources to schools, expanding choices and competition in education, increasing accountability for students and teachers, making professional development and teacher credentials more rigorous, easing entry into the teaching profession, curricular reforms, and others related to these (United Republic of Tanzania \{URT\}, 1995). Though these initiatives might have been in place for quite some time, myths remain to be issues of discussion in any education practice at any context because they tend to shape how 
people think and behave (Clark, 2004; Jay \& Marcus, 2005; Shokpeka, 2005). As important components of educational practice myths happen to shape the individual expectations and the value attached to education, the role which suggests the fact that the contemporary status of the Tanzanian education sector has a lot to do with what the stakeholders believe in (i.e. the myths attached to what they believe in education).

In an attempt to trace the origin of myths, Combs (1979), Greene (2005), Harmes, Huijser and Danaher (2015) argue that myths arise from man's attempt to externalize and communicate his inner intuitions and they survive not because they are true but because they are emotionally satisfying aids to contentions which are difficult or even impossible to justify on coldly rational grounds. In this context myths are described to communicate several different, divergent, and sometimes contradictory meanings about a particular phenomenon. In addressing the mythical impacts in education it is evident that they happen to shape the educational thoughts, policies and practice (Clark, 2004). In so doing, they negatively influence understanding of the nature of problems in schools and play a great role in providing directions of practice on how to act against certain dilemmas (Marcella, Kyalo, Kadenyi, \& Kegode, 2009). Despite such limiting impacts of myths in the education practices, stakeholders still hold these negative views as a result of what they believe to be true even when it is not true (Greene, 2005).

The evidence from the classical scholars reveals that the question of defining myths seems indeed to be difficult and therefore avoided (Des Bouvrie, 2002; Halpé, 2010). Some scholars have considered myths as meaningless and abandoned them altogether (Jay \& Marcus, 2005; Marcella, Kyalo, Kadenyi, \& Kegode, 2009). Though myths may seem to be not important in education practice, they remain to have a powerful response in education if the stakeholders accept them as valid and meaningful (Morales, 2013). This means that to people who accept them, myths are usually used as means to cope with difficulties of life as they create an idealized picture of whatever aspects of life they talk about (Miller, 2014).

At some points myths are identified as being based on fictions and sometimes based on lies (Miller, 2014; Zaidi, 2008). Although myths seem to be untrue lines of thoughts that are loosely based on concrete facts, they appear to communicate some very real truths to the people who accept it as a living metaphor (Hirschheim, \& Newman, 1991). As such myths are neither judged by whether they cannot factually be proven true nor are they judged based on literal accuracy but rather myths seem to be judged basing on their power to move us emotionally; to challenge or reassure us intellectually; to shape, reshape, or reaffirm the way we experience the world (Cohen, 1969; Shokpeka, 2005).

In contrast to other views Lincoln (1999) considers myths as both untrue and true narratives. This view identifies the concept of myths as beliefs that people adopt because they have an air of plausibility, believed to be true, occupy an enduring powerful position in practice, and they are consistently surviving even if there is no pieces of evidence (Claude, 1981; Hirschheim \& Newman, 1991). In the same line of view different literatures identify myths as sorts of lens through which a certain particular community not only sees the world but also is able to tell the following: what can be accepted as factually true and what must be considered 
false; what to pay attention to and what to ignore; how to interpret the daily experiences; and how can the truth can be viewed (Chernus, 2012; Cohen, 1969). While in some ways myths are considered as traditions or accustomed accounts of truth that have been passed down from generation to generation as beliefs; in a rationalist sense anything mythical is considered absolutely untrue.

It can therefore be argued that the analysis of debates about myths appears to be divided into three major categories including:

a) Those that seek to challenge and transform persistent myths with the aim of dispelling stereotypes (e.g. Hawes, 2014).

b) Those focusing on interrogating myths which in this context "myths" are considered as popular misconceptions in education (Clark, 2004; Luft, 1999).

c) Those that are based on conceptualizing the concept of myths for the sake of understanding their nature, and their impacts in education practice (Des Bouvrie, 2002; Halpe, 2010; Jay \& Marcus, 2005).

Generally, the debate about myths ranges from analysis to deconstruction and from challenging the myths to dispelling them by appropriate mode of thought or practice. Arguably, the discussion about myths seems to fall into areas of faith, beliefs, and unexamined opinions that happen to guide a certain practice or thought. In the context of this paper it appears that the efforts to address the myths in education might not be successful if a careful study about their nature, origins, dimensions, and impacts in education practice is not done properly.

\subsection{Myths in Education}

Similar to other influential issues in education, myths have emerged in form of ideas and approaches of practice in education, the occurrence which seem to gain popularity in education practice, even when there is little factual support for their plausibility (Luft, 1999). Some scholars have warned that although these ideas tend to explain phenomena, they seem to: use a common language, and considered plausible in educational practices; adversely influence education practice and limit the correct understanding of what quality education should offer (Combs, 1979; Greene, 2005). Similarly, Luft (1999), and Clark (2004) have mentioned that the impact of the prevailing myths in education remains to be a challenging concerns that require immediate solution.

Different attempts including international conferences, individual authors, and social gathering have been done attempting to understand the nature, dimension and impacts of myths in education (Alhaidari \& Bhanegaonkar, 2012; Combs, 1979; Greene, 2005). Despite such attempts the literature has identified that no one has yet been able to come up with a simple definition of myth that includes everything the definer regards as myth and excludes everything else (Caldwell, 1989; Zaidi, 2008). As such it appears very difficult to arrive at a single definition of myth as they happen to have multiple forms in that: while on one hand myths seem to behave like stories about ancient events that define and sustain notions of 
present community; on the other hand they appear as fabrications or acts of false speech, yet, ideologically persuasive.

In closing the difficult to address myths in education Trice and Beyer (1984, p. 655), and Clark (2004) identify myths as unquestionable beliefs about the practical benefits of certain techniques and behaviours, which although they are not supported by demonstrated facts they able to provide ways of classifying and organizing reality. In this line of view myths are therefore are viewed as plausible lines of inquiry that provide explanations, reconcile contradictions, and help resolve dilemmas. Despite having the function to explain, express, maintain solidarity and cohesion, legitimize and communicate ideas, mediate contradictions, and provide narrative to anchor the present to the past experiences in education; they are known to distort images and misdirect attention (Trice \& Beyer, 1984). These functions are carried out with various forms of myths which are discussed in the section that follow.

\subsection{Forms of Myths in Education}

Several misconceptions appear to be propagated about QE, a situation which has seem to have elevated a need to put the debate to rest, debunk and dispel some of the more common myths about QE (Harmes, Huijser, \& Danaher, 2015). But before such a discussion can happen it is important to understand some vital forms and levels of myths in education. According to Alhaidari \& Bhanegaonkar (2012) and Chernus (2012) myths in education appear to be categorized as follows: Firstly, pedagogical myths which teach people how to live human lifetime under different circumstances. Secondly, fiction based myths which blend some empirical truth with fiction. This type of myths is the most damaging one in theory and educational practice because; the more truth they contain, the more convincing they are and the harder they become to refute. Again this kind of myths is more influential in practice than any other type myth. Thirdly, lie based myths which are the types of myths that are easily identified from the empirical facts. These myths can easily be debunked by fact, which places some limit (at least in theory) on their influence. Fourthly, mystical myths which tend to attract people's attention to the mystery and wonder in the creation of the universe and beings. Fifthly, sociological myths which basically mention the ethical laws which give people a charter to follow in their behaviours and practices. These types of myths reflect the features of the ideal human behaviour and the reality. Finally, are the cosmological myths which essentially show the shape of the universe and its content by providing a complete explanation of the universe and its content. Such a diverse nature of myths presents a need for a carefully study about them, to identify their origins and dimensions, recognize their existence, and plan new strategies to dispel them.

\section{Aim of the Study}

This study aimed at interrogating myths as misconceptions in education; understanding their impacts in education practice and identifying the appropriate ways to address them. It is expected that, the discussion in this paper will initiate and stimulate debates inform of conversation and discussion among academic community about the effective direction for QE. The author's interest in examining the respondents' views on the desire to provide QE was built on the premise that there were a lot of myths among stakeholders that needed to be 
identified, and dispelled if the goal of providing QE was to be achieved.

\section{Methodology}

The study was informed by the researcher's own experiences as an education researcher and the interviews of three key educational stakeholders such as students, parents and secondary school teachers. While the educational stakeholders' understanding about QE were examined to identify the existing myths in their responses; the researcher's experiences and the literature were used to identify the possible impacts of myths in education practice and providing a suggestive explanation on how to address them. The respondents were obtained using semi-structured interviews and focus group discussions in which 100 respondents in a composition of 24 teachers, 24 parents, and 52 students were involved in the discussion about the QE in Tanzanian secondary schools.

The respondents were sampled from two regions in Tanzania. While teachers and parents were involved in the interviews, the students were involved in the focus group discussion. The sampling strategy was both purposively and opportunistic, and the author acknowledges that the sample size was limited; as such no formal claim of generalization in this paper should be taken. This is because claims made in this paper do not necessary match the views from other categories of education stakeholders apart from those visited. The views of the stakeholders visited were also likely to have been influenced by their geographical location, ethnicity, the experiences and values, and the preferences attached to the education offered.

Despite such limitation, the author believes that the evidences and interpretation presented in this paper are still valuable, because they point out some interesting elements related to misconceptions regarding QE that are worthy of consideration by the education community. Otherwise a more formal and generalizable validation of "myths" by surveying a large and diverse sample of education stakeholders can be pursued.

The paper holds an expectation that the brief commentaries of this study will prompt educators and policy makers to consider different ways of identifying, addressing and dispelling the present myths in education.

As for this paper, each myth presented in this paper is followed by research evidence and the discussion of related studies and its implications for the quality education practice. Also the discussion echoes two major foci: The focus on myths that influence the stakeholders' knowledge and beliefs about QE and the focus on myths that influence the practice of education.

\section{The Evidences of Myths Regarding QE}

The findings showed that though most respondents' voices of dissatisfaction on the way education system was operated were clear; an analysis of their cries showed a strong connection to myths that clearly happened to shape their views regarding QE. The existence of these myths appeared to produce conflicting opinions, disagreements, mis-conceptions, and multitude of beliefs among respondents, a situation which in turn evolved into full-blown interference in the understanding of QE. In an attempt to find out how such myths could be 
addressed, most respondents took an ambivalent attitude towards QE and much of what they thought about QE was nothing more than a myth. The subsections that follow identify the major myths that were evidently revealed in the findings and their implications towards provision of QE in Tanzanian junior secondary schools.

\subsection{Myth Related to Educational Funding}

The stakeholders still held the fiction or bad myth that more money meant better schools. Though this might be true, the experiences revealed that unlike the increase in educational budgetary expenditures in Tanzanian over the past several decades, the performance has not mirrored such increments in funding (Mkulo, 2011). For instance while it is always a common issue about education budget cuts per pupil and the spending adjusted for economic deflation the reality is that, the budget allocated for education sector in Tanzania has tripled over the last 15 years from $15.3 \%$ of total budget in 1995/96 to 20\% in 2013/14 being among the highest budgetary allocation in sub-Saharan Africa (URT, 2014).

Despite such an increase in education spending, however, has not yielded a doubling result in educational achievements; that is, the students' achievements have not been reflected by the increase in funding. For example the performances in junior secondary schools (JSS) seem to fall, along with graduation rates (Osaki et al., 2004). It would have been expected that if schools only needed more money to improve, then with an increase in spending the students' achievements could have improved; a situation which has been a dream for some time now. It can be argued that funding is not a problem but the far more important issue is how such funds even if small are spent. As it is now, it appears not possible to have better education outcomes when there is poor allocation and misuse of such funds (Rajani \& Sumra, 2003). This fact is described better in Figure 1 which shows an analytical cartoon of the typical flow of funding and how such funds have been utilized as summarized by one of the respondents.

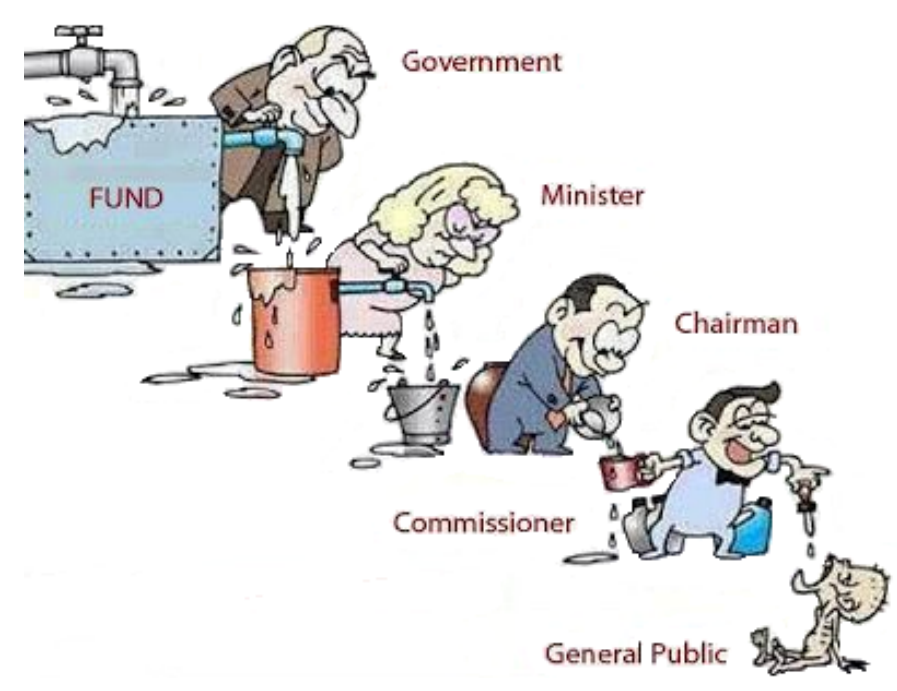

Figure 1. The flow of funds in education 
As it can be seen from Figure 1 the "general public" which stands for a school receives just a drop of the huge funds allocated. With such an amount of funding going into school from the bigger pool of funds available for education improvement nothing positive can be expected from the original invested funds. It argued important to understand that without stronger management of funds and concerted efforts for making sure that such funds are more effectively utilized, and monitored there is no reason to think that the next increase in budgetary allocation in education will improve the situation in schools. Deductively it can be argued that it is not the increase in funds in schools; education that are to be cried out but the monitory process of such funds.

\subsection{Myth Related to the Teaching Profession}

The respondents also echoed a sociological myth towards teaching in that: the teaching profession was considered an easy profession that anyone can do and be into. Such a myth regarding teaching has welcomed professional mongers who have made their way into the profession despite their deficiency in skills and knowledge about teaching (Komba \& Nkumbi, 2008). It was also evident in the documents reviewed that the recruitment pass mark in some of the public teacher training colleges was lowered to the point of recruiting the individuals from the failed group who would later be expected to produce quality teachers (MOEC, 2000). The respondents confirmed that the worst thing was an approval by the Ministry of education and vocational training (MoEVT) which at one time it announced employment opportunities to whoever had a degree in any field to volunteer teaching in JSS. It was also confirmed that the similar practice is repeated in teacher training colleges where the number of years for teacher training had been reduced to one year for Diploma in Education; a situation which appears to have resulted to the trainees achieving a half dose of what was supposed to be offered. It is argued in this section that probably the value of teachers has been mythologically defined consequently having a wrong impression of who are good teachers and what it takes to having quality and competent teachers.

The findings also revealed that teachers in JSS were treated like knowledge-delivery machines whose tasks were not more than preparing students for high-stakes examinations. Such a myth comes with other disrespectful view about the profession by regarding it a "losers' profession". Such views are contrary to the views by Kitta (2004), and Komba and Nkumbi (2008) who regard the teaching profession as a resourceful undertaking inhabited by individuals who can fully understand their students and reflect upon, modifying and adapting their teaching, thus improving their strategies in a dynamic manner. It is argued important in this section that to solve the problems in the teaching profession there is a need to cleanse the professional underlying myths, the process which is likely to purify and add value to the teaching profession.

\subsection{Myth Related to Authority in Educational Matters}

The findings revealed the dominance of education system by the organized interests groups, such as teachers' unions, school-board associations, and education bureaucracies while parents, individual teachers and the students are left behind. This is a typical dominance of sociological myth whereby certain ethical laws are made to dominate and that all people are 
required to observe and adhere to (Harmes, Huijser, \& Danaher, 2015). The respondents especially teachers felt that the decision making process in education involved just few interests groups who appeared to be masquerading as advocates for the well-being of their students when in fact they are not different from most interest groups who have no good intention to education but their own interests. Komba and Nkumbi (2008), MOEC (2009) and Ngimbudzi (2009) identify that the existence of these interest groups have increased the possibility and easiness to infiltrate the harmful agendas into education and make them plausible as if they were true and can appropriately work for better results in education.

An example of such interest group in education is a policymaking sector which was complained to be composed of only few individuals. This interest group was described to be exceptional and with all the power and authority when it comes to advocating what to teach and learn and how to do it (MOEC, 2009). Such concentration of authority to just few individuals appears to interfere with the efforts towards improving the power relations within the MoEVT and among other partner industries. While acknowledging that is quite important to have the coordinating team for education matters, it is also essential to have all stakeholders empowered regarding all education issues that happen to touch their daily lives (Gnanam \& Stella, 2015). This could solve a number of problems including false infiltration of harmful agendas into the education that has been exercised by few organized-interests groups in power who have been pretending to be advocates for the Tanzanian education.

\subsection{The Myth Related to the Emphasis on Examinations}

This is perhaps the most insidious and dangerous cosmological myth surrounding the Tanzanian JSS today (Education Sector Performance Report, 2010). Most respondents identified a situation where examinations have become the prime drivers of everything that happens in schools. The schools were described as no longer centres for knowledge and skill acquisition but centres where training to pass examination is provided and where academic certificates can be bought and sold. This situation seems to have transformed schools into certificate shops. In the report by MOEC (1999) and Hamilton, Mahera, Mateng'e, and Machumu (2010) it is confirmed that schools are rewarded or sanctioned based on national examination results, a situation which not only attaches too much emphasis on testing but also forces teachers to teach, to the test, and not worrying about whether students are really learning. The argument about too much emphasis in examination presents several basic questions that this paper regards to be important insights to think about. These include: Is it all about producing data rich but poor useful results that we want? Which one is worth considering between the level of students' capability and the mere statistics? Which one is worth celebrating between the added value provided by a school and the absolute scoring in exam papers? Which one is more important between seeking for value of formative assessment procedures which is based on diagnosis and development and the summative assessment which can become purely testing?

It is argued in this paper that the attempts to answer these question in hurry has hampered the efforts towards developing appropriate assessment procedures in Tanzanian education that is contextually, cultural and diverse responsive. Again as argued by (Green, 2005; Terenzini, \& 
Pascareua, 1994) myths around assessment procedures play a great role in influencing the assessment practices. Though schools have been attempting to polish their assessment practices running such practices without deep reflecting back on whether such practices assist learning or not, is deemed in this paper not only frustrating but also waste of talents among learners which could have been identified by quality learning and assessment procedures in their early years of learning.

\subsection{Myth Related to the Fluency in English Language}

Despite the fact that Tanzania is a multi-cultural and multi-language country; the country has been using English as the only official language for instruction in secondary education (URT, 1995). The belief that happened to cloud most of parents' minds was that knowledge is English. Parents equated fluency of English to QE. For them if a child attended a school program and in short time he/she could speak English at the end of it then that was a reason enough to describe the standard of education provided. Realistically this is a myth which compels their emotions towards reacting to a single aspect in education in the expense of the others.

This myth was also confirmed by teachers who identified that some primary schools whose official medium of instruction was Swahili had started using English to address the mythical demands. It is argued in this paper that yes Tanzanians being part of the global family cannot ignore English; and it is true that English is still the leading academic language of the world; furthermore, it is undeniable fact that English language is widely spoken almost throughout the world and is number one in commercial transactions. But most parents and other education stakeholders appear to miss the point that teaching English and teaching in English are two different things. While the first contention supports the importance of teaching English as an international language, additional language and a schools subject for that matter, the other contention talks about using it as the medium of instruction and the best way to educate learners (another myth).

The use of English as a medium of instruction in some primary schools and all secondary schools in Tanzania appear to be so distracting on learning in JSS. This is supported by the studies by Qorro (2004) and Brock-Utne (2005) who reveal that most teachers and secondary school students are seriously handicapped when it comes to using English as the language of instruction. It is argued in this section that because firm grasp/understanding of the subject matter is a central to the quality of education, such learning experience can only be achieved when teachers and students understand the language of instruction. This creates an opportunity to think about another alternative such as taking advantage of Kiswahili as an upcoming favourite language in East Africa and Africa at large because using this language is likely to improve the quality of education in the country.

\subsection{Myth Related to Quantity versus Quality Labels in Education}

In recent times Tanzania has witnessed the quantitative increase of both primary and secondary schools as a response to the government's call to build junior secondary schools at every District (URT, 2014). However such an increment of schools has been described by 
some education stakeholders as malicious to the provision of QE (Hakielimu, 2008). Placing too much emphasis on quantity than quality of education can be described as factious myth which is left to operate despite its negative impacts on quality of education (Wolf, 2002). For instance with the envision of the Government's Primary Education Development Plan (PEDP) and Secondary Education Development Plan (SEDP) in 2000s; more schools and classrooms were built and enrolment numbers of students significantly did shoot up. Unlike the PEDP's and SEDP's aim of showing a commitment to improving educational quality, the Government's aims was largely focused at issues of quantity which involved enrolling more children in schools, finding more teachers, and creating more space for them (URT, 2014). The conflicting difference on the aims between the government and that of the two educational development plans reveal an existence of myth which appears to shape their interest. As a result of this side-lining effect towards QE more funds seem to allocated for building schools and more children are entering schools, but the teaching and learning that actually takes place inside those schools especially in ward secondary schools is discouraging (Uwezo, 2010). It is argued in this section that the mere increase in access to education, while necessary, is not sufficient for ensuring improvement in individuals 'personal lives or meeting the prospects of the country as a whole. As such appears inevitable to shift from quantity to quality based visions in education and probably looking for better balance of the two could do well to in serving this imbalance.

\subsection{Myths Related to the Importance of $Q E$}

The respondents especially students seemed to believe that good educational outcomes meant good employment, a situation which has turned the students to work hard and excel only to be through with the school system and find themselves with no job, and not able to earn a living. It is however argued by Jay and Marcus (2005); Marcela, Kyalo, Kadenyi, and Kegode (2009) that the graduates' failure to get decent jobs cannot be directly attributed to QE provided but to the myth held in such journey of training and the availability of opportunities present in the job market. In a similar view the Tanzanian education system is complained by most respondents for being too academic to the extent of neglecting vocational skills which provide a learner with self-reliant and self-employable skills. The neglecting of vocational skills can also be related to the time when the Tanzanians neglected the vocational traditional education with the influence of the colonists who made the Tanzanians adopt the academic education so that they would get 'white-collar' jobs whereas the manual jobs would be taken by those who were not learned (Nyerere, 1968). It is therefore argued that while the relationship between QE and earning good job after graduation look too distant; securing good job in Tanzania is a multi-influenced aspect which cannot be explained using only the lenses of acquisition good skills.

\subsection{Myth Related to the Availability of Laboratories and Practical Work}

It is evident that laboratory investigations are vital in learning (Hamilton et al., 2010; Mafumiko, 2004). The findings also reveal that the respondents were emphasizing the presence of lab activities in schools. This fact was also consistent among teachers and students who believed that when students manipulate materials, collect data, and answer 
questions, they learn the essential concepts inherent in the investigations. This view appears to be a myth because most of laboratory experiences are highly structured, confirmatory, guided and teacher-directed and they offer little opportunity for students to construct their own knowledge (Gabel, 1994). Typical laboratory experiences in Tanzanian JSS do not account for students' prior knowledge, nor do they force students to confront their current scientific ideas.

Given this fact Saunders (1992) argues that in order for students to learn certain concepts, they need to have experiences that reveal and build upon their current cognitive schemas; provide opportunities for students to construct their own understanding of concepts through events that challenge preconceived ideas. This would mean re-visioning the way science labs are viewed and weighed so that such lab activities may help students to make sense of the daily lives.

From this discussion it can be noted that many education stakeholders are in the grip of several myths which in this context are identified as mistaken ideas that defy the facts and shift the attention to most appropriate direction. The continued prevalence of these myths in education shows a potential limitation to effective practice of education. This means that as long as they are perpetuated (directly or indirectly), they are likely to continue to influence the efforts towards effective teaching and learning and that the students will also be negatively influenced in their achievements. Luft (1999) and Hawes (2014) argue that it is not enough to challenge these myths, but rather there is a need to: acknowledge that they exist and commit to their revision; prepare with ample time for change; surround ourselves with colleagues who are also in the process of challenging these myths, and remember that the only myth that does not change is the myth that goes unchallenged. It is important to understand that by discussing commonly held myths and misconceptions about QE is likely to help in dispelling them and hence maximizing the potential outsourced from QE.

\section{Implications of Myths in Education Practice}

Some of the myths discussed in this paper are so convincing that they become subtle obstacles and/or obvious barriers to having a common focus to provide QE in schools. As such they reduce the likelihood that stakeholders will think and consider adopting other ways to improve the provision of QE in school. In the context of this paper the effort to dispel myths implies that:

$>$ We cannot afford to ignore the reference underlying myths in education and the education sector in general. In a similar line of interest Calame (1999) suggests that we should abandon the essentialist connotations of myth so as to include the argumentative and rational functions (the pragmatic that is the rhetorical function) of narrative manifestations of symbolic thought.

$>$ Because myths provoke a sense of double-vision in relation to characterization and they plot that function through irony; the failure to address these myths it is likely that myths will lead to emotional reactions, including anger, anxiety and fear of change for better practice among stakeholders. 
$>$ It is time to shift to basics of perfection in education by addressing all myths clouding the education sector because they have been identified as; contributing in slowing down the acceleration towards success, reflecting a dim view of the future in the provision of QE, and that they lead to misinformation and misguided practices that disadvantage the stakeholders from being effective facilitators of learning.

$>$ By removing the myths that undercut the stakeholders' confidence and effective approach to providing QE is likely to help analysing the rhetoric persuasion or the affective power of myth and therefore leading us to the creed for relevant and meaningful QE.

$>$ When myths are left to exist and used as framing devices to narrate how education should be practiced, all efforts towards provision of quality education experiences and moments are likely to be propelled by a particular mythical force (Li \& Akins, 2004). As such any attempt to address them is likely to fail because at this point myths will have been prefabricated to become frames of meaning which the reader can not recognize.

$>$ Because myths function by invoking a sense of sacredness, and oracular role in education practice with a power of archetype in service of collective socio-cultural practice and belief systems, it is important to careful understand how concerns based on these myths appropriately addressed and prevented to interfere with the effective and appropriate insights about QE.

As vehicles of collective communal narratives, myths represent the culturally formed narratives on archetypal processes (Wolf, 2002). This characteristic of myths makes them to possess a numinous and emotional impact on the individual's psyche in the recognition of their presence. As such their identification and efforts to dispel them should be hinged at both individual and societal levels.

It is a general concern of this paper that by understanding the concern of myths and their impacts in education is likely to help in producing positive impacts towards shedding light about their existence and impacts they have in education (Harmes, Huijser, \& Danaher, 2015). It is just unfortunate that solutions to these myths as pursued by education reformers hinge on the assumptions that are wrong, a situation in which even the best laid plans have been going astray. Probably the promising and easiest way to respond to the myths about QE is by investing on a comprehensive study about their prevalence with established efforts to dispel them.

This initiative of dispelling myths could start from the stakeholders being aware of the existing myths and be ready to unlearn them (Hawes, 2014). In such initiative quick and easy solutions are not appropriate for a complex problem of this kind. The careful collaborative rethinking of better ways to dispel them is likely to help in easing the process.

\section{Conclusion}

This paper has revealed that the existence of myths in Tanzanian education play a great role in influencing the practices in education, a situation which ultimately determine the quality of education in Tanzanian schools. It is argued that perpetuating them (directly or indirectly), 
will mean a confinement into the darkness margins about QE and the proper ways to deliver it in schools. The discussion has shown that myths can become self-fulfilling prophecies if left unexamined and unaddressed. With mythical interferences in Tanzanian education sector the current education system not only requires an insulation of education sector from unnecessary impractical beliefs but also a need for a holistic reorientation, re-polishing, re-engineering and rebranding of education sector, especially the planning, implementation and evaluation processes, if quality of education is to be achieved. This can only be possible if there is clarity not only on what the Tanzanians want from their schools but also what areas Tanzanians are falling short of their expectations.

It is also argued important to abandon the myths attached to education and embrace the alternative working pieces of thoughts if the current children in schools are to be served from gaining less knowledge a situation that might limit their confidence levels to face their futures. This could be done not by challenging the existing myths with quick fix strategies or with right and wrong answers; but rather an ample time is needed in identifying the myths and acknowledging that they exist, then commit to their revision. Such striking efforts are likely to help people to correctly figure out what is working so well in education and do more of it.

It is important to understand that this paper provides an opportunity for teachers, parents, and students to confront their myths towards QE. In so doing it may likely help in encouraging them to become more effective and proactive in contributing to provision of QE. The discussion about this intricate problem was not based on providing all answers and solution to the myths in education but to offer a light on how they look like and provide some clarification on how they can be addressed.

The author also reminds that because the paper is based on explorative evidences, its interpretations should not be viewed as definitive validation of or falsification of myths identified; rather a sensitization to the entire education community about some questionable assumptions that pervade their thoughts regarding QE and the education sector in general. While the author considers his work as among the few initiatives for dispelling the myths in education, clearly much remains to be explored in this nascent and vital arena of myths in education.

\section{References}

Alhaidari, A., \& Bhanegaonkar, S. G. (2012). Meaning, Origin and Functions of Myth: A Brief Survey. International Journal of Social Science Tomorrow (IJSST), 1(3).

Caldwell, R. (1989). The Origin of the Gods: A Psychoanalytic Study of Greek Theogonic Myth. New York: Oxford University Press.

Chernus, I. (2012). The Meaning of "Myth" in the American Context. Essays about America's national myths in the past, present, and future. Mythic America: Essays.

Clark, J. (2004). Educational Myths as a framework for Education Policy: Towards a New Myths. New Zealand Annual Review of Education, 13, 5-19.

Claude, N. P. (1981). Walter Burkert and the Meaning of Myth. Cleveland State University. 
The Journal of Religious Studies, 9(1), 10-18.

Cohen, P. S. (1969). Theories of Myth. Man. http://dx.doi.org/10.2307/2798111

Combs, A. W. (1979). Myths in Education: Beliefs that Hinder Progress and their Alternatives. Boston: Allyn and Bacon.

Des Bouvrie, S. (2002). The Definition of Myth. Symbolical Phenomena in Ancient Culture. The Norwegian Institute at Athens.

Gabel, D. (Ed.). (1994). Handbook of Research on Science Teaching and Learning. New York: Macmillan Publishing.

Gnanam, A., \& Stella, A. (2015). Myths and Realities: Distance Education in India. International Higher Education, 38, 18-19.

Greene, J. P. (2005). Education Myths: What Special-Interest Groups Want You to Believe about Our Schools and why it isn't so. Lanham, MD: Rowman \& Littlefield.

Halpé, A. (2010). Between Myth and Meaning: The Function of Myth in Four Postcolonial Novels. A doctoral thesis. University of Toronto.

Harmes, M. K., Huijser, H., \& Danaher, P. A. (2015). 1 Demythologizing Teaching and Learning in Education: Towards a Research Agenda. Myths in Education, Learning and Teaching: Policies, Practices and Principles, 1.

Harmes, M. K., Huijser, H., \& Danaher, P. A. (Eds.). (2015). Myths in Education, Learning and Teaching: Policies, Practices and Principles. Palgrave Macmillan. http://dx.doi.org/10.1057/9781137476982

Hawes, G. (2014). Rationalizing Myth in Antiquity. Oxford University Press. http://dx.doi.org/10.1093/acprof:oso/9780199672776.001.0001

Hirschheim, R., \& Newman, M. (1991). Symbolism and Information Systems Development: Myth, Metaphor and Magic. Information Systems Research, 2(1), 29-62. http://dx.doi.org/10.1287/isre.2.1.29

Jay, P. G., \& Marcus, A. W. (2005). Education Myths. Rowman and Littlefied Publishers, Inc.

Kitta, S. (2004). Enhancing Mathematics Teachers' Pedagogical Content Knowledge and Skills in Tanzania. Doctoral dissertation. Enschede: University of Twente.

Komba, W., \& Nkumbi, E. (2008). Teacher Professional Development in Tanzania: Perceptions and Practices. Journal of International Cooperation in Education, 11(3), 67-83.

Li, Q., \& Akins, M. (2004). Sixteen myths about online teaching and learning in higher education: Don't believe everything you hear. TechTrends, 49(4), 51-60. http://dx.doi.org/10.1007/BF02824111

Luft, J. A. (1999). Challenging myths: Questioning common myths about science education. The Science Teacher, 66(4), 40-43. 
Mafumiko, F. M. S. (1998). The Role of Practical Work in Chemistry Education in Tanzania: Exploration of Current Practices and Potential Alternatives (Master Thesis. Enschede: University of Twente).

Marcella, M., Kyalo, W. B., Kadenyi, M., \& Kegode, G. (2009). Myths in education: A Kenyan perspective. Moi University in Kenya. Educational Research and Review, 4(3), 071-077.

Miller, J. E. (2014). Ancient Greek demythologizing. Myth and Scripture: Contemporary Perspectives on Religion, Language, and Imagination (p. 213).

Mkulo, M. (2011). Country Budget Speech for the Financial Year 2011/2012. Dar es Salaam: Ministry of Finance.

MOEC (Ministry of Education and Culture). (1999). Education for all assessment: National report of the united republic of Tanzania. Dar es Salaam.

MOEC (Ministry of Education and Culture). (2000). Teacher Education Master Plan. URT: Dar es salaam.

MOEC (Ministry of Education and Culture). (2009). A Draft Bill Providing for Registration, Teaching Profession, and Establishment of Teachers' Professional Board. Dar es Salaam. Ministry of Education and Vocational Training.

Morales, S. S. (2013). Myth and the construction of meaning in mediated culture. An International Journal of Pure Communication Inquiry, 1(2), 33-43. http://dx.doi.org/10.17646/kome.2013.13

Ngimbudzi, F. W. (2009). Job Satisfaction among Secondary School Teachers in Tanzania. University of Jyvaskyla, Department of educational science.

Nyerere, J. K. (1968). Ujamaa- Essays on Socialism. Oxford University press. Dar es Salaam.

Osaki, K. M. (2004). Reflections on the state of science education in Tanzania. In K. M. Osaki, K. Hosea, \& W. J. W. Ogevanger (Eds.), Reforming Science and Mathematics Education in Sub Saharan Africa. Obstacles, Opportunities. Dar es Salaam \& Euschede. TEAMS Project.

Osaki, K., Hosea, K., \& Ottevanger, W. (Eds.). (2004). Reforming Science and Mathematics Education in Sub-Saharan Africa: Obstacles and Opportunities. Dar es Salaam: TEAMS, University of Dar es Salaam.

Qorro, M. (2004). Popularising Kiswahili as the language of instruction through the media in Tanzania. In B. Brock-Utne, Z. Desai, \& M. Qorro (Eds.), Researching the Language of Instruction in Tanzania and South Africa. African Minds. Cape Town: One world books.

Rajani, R., \& Sumra, S. (2003). Is extra funding for primary education making a difference? Conceptual and measurement challenges. HakiElimu Working Paper Series No. 3. Tanzania Haki Elimu.

Saunders, W. (1992). The constructivist perspective: Implications and teaching strategies for science. School Science and Mathematics, 93(3), 136-141. 
http://dx.doi.org/10.1111/j.1949-8594.1992.tb12159.x

Shokpeka, S. A. (2005). Myth in the Context of African Traditional Histories: Can it be Called "Applied History"? History in Africa, 32, 485-491. http://dx.doi.org/10.1353/hia.2005.0023

Terenzini, P. T., \& Pascareua, E. T. (1994). Living with myths: Undergraduate education in America. Change: The Magazine of Higher Learning, 26(1), 28-32. http://dx.doi.org/10.1080/00091383.1994.9938488

Trice, H. M., \& Beyer, J. M. (1984). Studying organizational cultures through rites and ceremonies. Academy of Management Review, 9, 653-669.

URT (United Republic of Tanzania). (1995). Education and Training Policy. Ministry of Education Culture, Dar Es Salaam.

URT (United Republic of Tanzania). (2014). A General Report of the Controller and Auditor General on the Performance Audit (VFM) Reports for the Period Ending 31st March, 2014. United Republic of Tanzania.

Uwezo. (2010). Are our children learning? Annual Learning Assessment Report, Tanzania.

Wolf, A. (2002). Does education matter? Myths about education and economic growth. Perspectives, 6(4), 115-118.

Zaidi, A. S. (2008). Legitimizing Myth and the Search for Meaning. Theory in Action, 1(4), 114-122. http://dx.doi.org/10.3798/tia.1937-0237.08021

\section{Copyright Disclaimer}

Copyright for this article is retained by the author(s), with first publication rights granted to the journal.

This is an open-access article distributed under the terms and conditions of the Creative Commons Attribution license (http://creativecommons.org/licenses/by/3.0/). 